\title{
Distinguished Reviewers
}

J Gen Intern Med 24(12): 1341

DOI: $10.1007 / \mathrm{s} 11606-009-1171-\mathrm{x}$

(C) Society of General Internal Medicine 2009

$\mathrm{E}$ ach year, the Journal of General Internal Medicine Editors identify those reviewers who did an exceptional job reviewing for us. To be included in this prestigious group, one must perform three or more reviews, return all reviews within 30 days, and receive no quality score on any review lower than 4 on a 1-6 Likert scale. This terrific and selfless work is critical to the quality of the Journal and to the authors who submit their manuscripts for review-and it is often unrecognized. We want to take this opportunity to recognize each of you and thank you for all of your efforts on behalf of JGIM.

The Editors

John Bulger, DO

Geisinger Medical Center

Danville, PA

Chayan Chakraborti, MD

Tulane University Health Services Center

New Orleans, LA

Sascha Dublin, MD, PhD

VA Puget Sound Health Care System

Portland, OR

Kimberly Engelman, PhD

University of Kansas Medical Center

Kansas City, KS

Robin Klein, MD

Emory University School of Medicine

Atlanta, GA

Sei Lee, MD

University of California, San Francisco School of Medicine

San Francisco, CA

Jennifer Potter, MD

Harvard Medical School

Boston, MD

Benjamin Powers, MD

Duke University School of Medicine

Durham, NC

Joseph Ross, MD

Mount Sinai School of Medicine

New York, NY

Michael Steinman, MD

University of California, San Francisco and San Francisco VA Medical Center

San Francisco, CA

Kristen Wells, PhD

H. Lee Moffitt Cancer Center \& Research Institute

Tampa, FL 